\title{
THE PLACE OF CONTRACT LAW IN RUSSIAN CIVIL LAW
}

\author{
Dmitry A. Turitsyn \\ Research Institute of History, Economics and Law, Moscow, Russian Federation
}

Introduction: the paper deals with the issue of determining the place of contract law in Russian civil law and legislation. Purpose: the author characterizes contract law in the system of Russian law. The analysis includes such aspects of classification as the difference between the contract and legal acts, etc., the name of the category of contract law and its system. Methods: the paper uses the general scientific, formal-logical methods and the method of system analysis. Results: the author defines the place of contract law as a subbranch of civil law. Conclusions: contract law of the Russian Federation is still under development and change; determining its place is important for further research and understanding the essence of the legal nature of contractual relations.

Key words: branch of law, sub-branch of law, Russian law, contract law, definition of contract law, place of contract law, civil law.

Citation. Turitsyn D.A. The Place of Contract Law in Russian Civil Law. Legal Concept, 2020, vol. 19, no. 1, pp. 108-111. (in Russian). DOI: https://doi.org/10.15688/lc.jvolsu.2020.1.15

\section{МЕСТО ДОГОВОРНОГО ПРАВА В РОССИЙСКОМ ГРАЖДАНСКОМ ЗАКОНОДАТЕЛЬСТВЕ}

\author{
Дмитрий Александрович Турицын \\ НИИ истории, экономики и права, г. Москва, Российская Федерация
}

\begin{abstract}
Введение: в статье рассматривается вопрос определения места договорного права в российском гражданском праве и законодательстве. Цель: автор характеризует договорное право в системе российского права. Анализу подвергаются такие аспекты классификации, как отличие договора от нормативно-правовых актов и т. п., наименование категории договорного права и его система. Методы: в работе использованы: общенаучные, формально-логический методы и метод системного анализа. Результаты: автор определяет место договорного права как подотрасль гражданского права. Выводы: договорное право РФ до настоящего времени находится в стадии развития и изменения, определение его места важно для дальнейших исследований и понимания сущности правовой природы договорных отношений.
\end{abstract}

Ключевые слова: отрасль права, подотрасль права, российское право, договорное право, определение договорного права, место договорного права, гражданское законодательство.

Цитирование. Турицын Д. А. Место договорного права в российском гражданском законодательстве //Legal Concept=Правовая парадигма. -2020. - T. 19, № 1. -C. 108-111. -DOI: https://doi.org/10.15688/lc.jvolsu.2020.1.15

\section{Введение}

Контрактное право существует уже несколько тысячелетий. Применение договоров на протяжении столь долгого времени объясняется многими причинами, наиболее суще- ственная из которых обусловливает применение договоров ввиду их гибкой правовой формы, способной описать различные по характеру, либо правовой природе общественные отношения. Иными словами, можно сказать, что главной задачей договора является регу- 
лирование правил поведения между отдельными субъектами - сторонами договора - в рамках действующего в рамках определенной юрисдикции закона, путем установления пределов их возможного и должного поведения, прав и обязанностей, а также последствий нарушения соответствующих требований посредством оговоренных санкций.

Переход к рыночной экономике и свободному рынку, предоставление существенной автономии хозяйствующим субъектам, создание сектора частной собственности в начале 90-х гг. ХХ в. в корне изменили роль и место договоров в правовой системе и существенно перестроили общественную жизнь как граждан, так и предприятий. Однако такой переход породил ряд проблем, связанных с пониманием и регулированием фундаментальных положений договорного права, включая определение места договорного права в отечественной правовой системе.

Для определения таких проблем на современном этапе развития контрактного права России необходимо определить место договорного права в системе отраслей российского права, а также обозначить дискуссионные вопросы правоприменения принципиально важных аспектов российского договорного права.

\section{Отличие договора от нормативно-правового акта}

Согласно ст. 420 Гражданского кодекса Российской Федерации (далее - ГК РФ) «договором признается соглашение двух или нескольких лиц об установлении, изменении или прекращении гражданских прав и обязанностей» [2]. Договор, в силу исполнения роли некого регулятора, схож с законом или иными нормативными актами, однако представляет собой самостоятельный источник регулирования общественных отношений. В данной связи в литературе неоднократно отмечались принципиальные отличия договора от правовой нормы - происхождение правовых правил и субъектный охват. Первая особенность указывает на тот факт, что договор является добровольным соглашением между сторонами, в то время как правовая норма санкционируется полномочными государственными органа- ми. Вторая особенность связана с тем, что обязанности, зафиксированные в договоре, распространяются лишь на стороны такого договора (договор может порождать права третьих лиц), а нормативно-правовой акт создает правило, обязательное для всех и каждого (исключение из этого круга могут устанавливаться самим нормативно-правовым актом) [1, с. 4]. Все это позволяет называть договорные правоотношения относительными [4, с. 207].

\section{Договорное право - институт или подотрасль?}

В отечественной юридической литературе существует несколько точек зрения относительно места договорного права в правовой системе Российской Федерации. Иными словами, данный вопрос является дискуссионным.

В соответствии с мнением ученых-цивилистов и специалистов в области договорного права М.И. Брагинского и В.В. Витрянского, договорное право представляет собой институт особенной части гражданского права. В отличие от них Е.А. Суханов полагает, что договорное право является институтом обязательственного права. Этот вывод он аргументирует тем, что договор является одним из оснований возникновения обязательственного правоотношения, наряду с односторонними сделками, причинением вреда лицу, неосновательным обогащением и т. п. [5, с. 35-83].

Несмотря на данные утверждения, мы полагаем, что договорное право является подотраслью в рамках отрасли гражданского права. На это указывает тот факт, что договорное право само по себе состоит из правовых институтов, затрагивает большой пласт общественных отношений, объединенных общей характеристикой. Следовательно, определение договорного права как подотрасли, на наш взгляд, является наиболее оптимальным и верным.

\section{Система российского договорного права}

Систему договорного права можно подразделить на отдельные разделы, включающие 
в себя ряд институтов. В частности, можно выделить раздел, посвященный общим положениям о договоре и обязательстве, а также раздел, посвященный отдельным видам обязательств, в зависимости от предмета договора. Таким образом, можно сделать вывод, что система подотрасли договорного права включает в себя общую и особенную части.

Общая часть посвящена фундаментальным положениям о договоре: дефиниции, признакам, принципам, структуре; порядку заключения, изменения и расторжения договоpa, его классификациям и т. п. [4]. Соответственно в отечественном гражданском законодательстве общей части договорного права посвящены гл. 21-29 раздела II, I первой части ГК РФ [2].

Особенная часть, в свою очередь, представляет собой сгруппированные правовые нормы, объединенные единым предметом и сущностью вида обязательства. В частности, мы можем говорить о наличии в особенной части договорного права таких институтов, посвященных отдельным договорам, как: купля-продажа, мена, дарение, рента, аренда, наем, подряд, оказание услуг, перевозка, заем, хранение, страхование, поручение и т. п. В отечественном договорном праве его особенной части соответствуют гл. 30-60 раздела IV второй части ГК РФ [3].

Таким образом, мы видим, что договорное право входит в отрасль гражданского права частной подсистемы права. При этом оно представляет собой его подотрасль, объединяющую отдельные институты, касающиеся вопросов регулирования договорного режима в Российской Федерации, а также отдельных видов обязательств, закрепленных ГК РФ.

\section{Выводы}

Подводя итоги, отметим, что договорное право в российском праве с развитием самого государства претерпело серьезные изменения и продолжает изменяться по сей день. Наиболее значимые изменения произошли после распада СССР и возникновения Российской Федерации. Прежде всего они были обусловлены широким распространением частной собственности, появлением широкого круга хозяйствующих субъектов и возникно- вением на просторах страны рыночной экономической системы.

Договор, несмотря на определенную схожесть с нормативно-правовым актом, имеет специфические особенности - происхождение правовых правил и субъективный охват, которые позволяют определить отношения, порождаемые им, относительными.

Договорное право является подотраслью отрасли гражданского права, частной системы права.

В системе договорного права можно выделить две части - общую и особенную. Общая часть включает в себя важные фундаментальные положения, а особенная - специальные положения о договоре и отдельные виды обязательств.

Правильное определение места договорного права в системе российского права позволит верно исследовать сущность правовой природы регулируемых им договорных отношений.

\section{СПИСОК ЛИТЕРАТУРЫ}

1. Брагинский, М. И. Договорное право: Общие положения (кн. 1) / М. И. Брагинский, В. В. Витрянский. - 3-е изд. - М. : Статут, 2001. - 476 с.

2. Гражданский кодекс Российской Федерации (часть первая) от 30.11.1994 № 51-Ф3 (ред. от 18.07.2019) (с изм. и доп., вступ. в силус 01.10.2019). Доступ из справ.-правовой системы «КонсультантПлюс».

3. Гражданский кодекс Российской Федерации (часть вторая) от 26.01.1996 № 14-ФЗ (ред. от 18.03.2019, с изм. от 03.07.2019). - Доступ из справ.правовой системы «КонсультантПлюс».

4. Даньшина, Н. А. Место договорного права в системе отраслей права / Н. А. Даньшина // Учетные записки Орловского государственного университета. - 2015. - № 2. - С. 207-210.

5. Суханов, Е. А. Российское гражданское право : учебник : в 2 т. / Е. А. Суханов, В. С. Ем, В. В. Витрянский. - М. : Статут, 2016. - Т. II. - 1206 с.

\section{REFERENCES}

1. Braginskiy M.I., Vitryanskiy V.V. Dogovornoye pravo: Obshchiye polozheniya (kn. 1) [Contract Law: General Provisions (Book 1)]. Moscow, Statut Publ., $2001.476 \mathrm{p}$.

2. Grazhdanskiy kodeks Rossiyskoy Federatsii (chast pervaya) ot 30.11.1994 № 51-FZ (red. ot 
18.07.2019) (s izm. i dop., vstup. v silu s 01.10.2019) [The Civil Code of the Russian Federation (Part One)]. Access from Reference Legal System "ConsultantPlus".

3. Grazhdanskiy kodeks Rossiyskoy Federatsii (chast vtoraya) ot 26.01.1996 № 14-FZ (red. ot 18.03.2019, s izm. ot 03.07.2019) [The Civil Code of the Russian Federation (Part Two)]. Access from Reference Legal System "ConsultantPlus".
4. Danshina N.A. Mesto dogovornogo prava v sisteme otrasley prava [The Place of Contract Law in the System of Branches of Law]. Uchetnyye zapiski Orlovskogo gosudarstvennogo universiteta [Records of the Oryol State University], 2015, no. 2, pp. 207-210.

5. Sukhanov E.A., Em V.S., Vitryanskiy V.V. Rossiyskoye grazhdanskoye pravo [Russian Civil Law. Vol. II]. Moscow, Statut Publ., 2016, vol. 2. 1206 p.

\section{Information About the Author}

Dmitry A. Turitsyn, Researcher, Research Institute of History, Economics and Law, Prosp. Michurinsky, 16/267, 119192 Moscow, Russian Federation, info@helri.com, i.am.newbie@hotmail.com,https://orcid.org/0000-0002-0574-8478

\section{Информация об авторе}

Дмитрий Александрович Турицын, научный сотрудник, НИИ истории, экономики и права, просп. Мичуринский, 16/267, 119192 г. Москва, Российская Федерация, info@helri.com, i.am.newbie@hotmail.com, https://orcid.org/0000-0002-0574-8478 